\title{
A Novel RP-HPLC method for simultaneous estimation of Dorzolamide and Timolol maleate in ophthalmic products
}

\author{
N. Sher ${ }^{1 *}$, N. Shafi ${ }^{1}$, H. Naseem ${ }^{2}$, M. A. Khan ${ }^{3}$ \\ ${ }^{1}$ Department of Chemistry, Faculty of Science, University of Karachi, Karachi, Pakistan 75270 \\ ${ }^{2}$ Department of Pharmaceutical Chemistry, Faculty of Pharmacy, Ziauddin University Karachi, Pakistan. \\ ${ }^{3}$ Saudi Pharmaceutical Industries, Industrial Area Police Station, Ayub Ibn Ishaq St, Sinaiya, Riyadh, Saudi Arabia,11383 \\ *Corresponding Author's Email: nawabsherafridi@gmail.com
}

\begin{abstract}
This research introduces an RP-HPLC method to estimate dorzolamide and timolol maleate quantitatively in the simultaneous mode. The stationary phase has consisted of A phenomenix ${ }^{\circledR}$ C18 column which gave satisfactory separation of these drugs when subjected to analysis, where in the mobile phase is composed of Acetonitrile:Buffer (20:80,v/v). The instrument was set up as such that the pump draws mobile phase at a flow rate of $1.0 \mathrm{~mL} / \mathrm{min}$ and monitored at $290 \mathrm{~nm}$ wavelength. Linear relationship of concentration of drugs vs. peak area was ascertained to assess linearity parameters and a correlation coefficient of more than 0.9995 for all the drugs was achieved when studied in a range of 10 to $1000 \mathrm{ug} / \mathrm{mL}$. The newly developed method showed high accuracy and precision with a percent recovery of $98.85 \%-101.23 \%$ and a percent relief standard deviation of $0.5-1.7 \%$. The optimized method was validated according to the guideline laid down by ICH and was successfully applied to quantitate both the drugs in bulk, raw material, eye drops formulation and in physiological fluids.
\end{abstract}

Keywords: Timolol maleate, Dorzolamide, RP-HPLC, Pharmaceutical eye drops.

\section{INTRODUCTION}

Beta-Blockers have been very useful in lowering intraocular pressure. They have proved to be important therapeutic agents for the treatment of angina pectoris, myocardial infection, glaucoma and ocular hypertension [1]. Ocular pressure above a certain limit damages the optic nerve, which causes blindness. Dorzolamide (DA) and Timolol maleate (TM) have been combined in a single formulation as an ophthalmic solution which constitutes a very useful combination of a topical carbonic anhydrase enzyme and a topical beta-adrenergic receptor blocking agent. Dorzolamide Hydrochloride (DA) is chemically defined as (4S,6S)-4-ethylamino-5,6-dihydro-6-methyl-4H-thieno(2,3b)thiopyran-2-sulfonamide 7,7dioxide monohydrochloride, structure shown in Fig. 1a. It is a carbonic anhydrase inhibitor, whereas, Timolol maleate (TM) is chemically (S)-1-tert-butylamino-3-(4- morpholino-1,2,5-thiadiazol-3-yloxy)propane-2-ol (Fig. 1b), is a wonderful beta-adrenergic blocking agent [2].

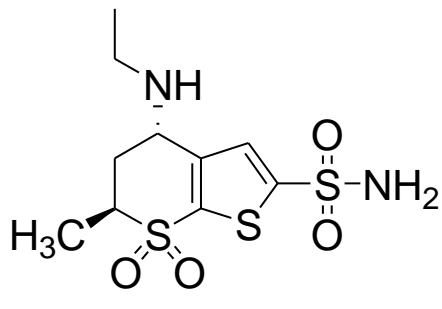

a

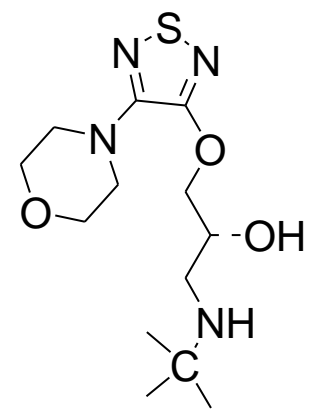

b

Figure 1. Structure of DA(a) and TM (b)

Potential benefits of these combinations include fewer drops per day and reduce expenses. A combination of DA and TM at various concentrations has been available in the market, requiring the simultaneous analysis of TM and DA in ophthalmic drops and ocular matrices. Pharmaceutical industries pay a great deal of importance to simultaneous analysis and a simple and straightforward method as such method reduces human hours in analyzing the product and implicates less environmental impact [3-6]. Literature survey reveals that there are few methods available for the determination of these drugs individually and simultaneously. These methods include high-performance liquid chromatographic with ultraviolet detection [7], spectroscopy [8], HPTLC [9], estimation as biological fluids [10], as well as other methods covering more than one individual drug in the simultaneous analysis [11-15]. In this study, we aim to develop an 
Sher et al., 2020

analytical method that could quantitatively analyze DA and TM in a simultaneous mood in a single run and proved to be an easy and straightforward protocol for simultaneous analysis of DA and TM in isocratic HPLC conditions.

\section{EXPERIMENTAL}

\subsection{Material and reagents:}

DA and TM were kindly gifted by a local pharmaceutical company, phosphoric acid, ammonium phosphate Merck (Germany), Acetonitrile (HPLC grade) were purchased from Fisher Scientific. An ophthalmic product labeled with active ingredients was procured from the local market. Double Distilled water filtered through a $0.45 \mu \mathrm{m}$ membrane filter (Millipore, Bedford, MA, USA) was used throughout the study.

\subsection{Apparatus:}

Shimadzu HPLC system comprising LC 20 AT pump, SPD 20A UV/VIS detector, SIL 10A auto-injector, with LC solutions software was used. Chromatography was achieved on a Phenomenex C18 HPLC column (4.6 x $250 \mathrm{~mm} ; 5 \mu \mathrm{m})$ maintained at $25^{\circ} \mathrm{C}$. Ultrasonic cleaner (Elmasoni E $60 \mathrm{H}$ ), Jenway $3240 \mathrm{pH}$ meter, and Sartorius TE2145 analytical balance were used in the research work. Throughout the work, only amber glass volumetric flasks were used in this research work.

\subsection{Chromatographic conditions:}

Analysis was performed at ambient temperature; isocratic conditions were set with a mobile phase consisting of Acetonitrile (HPLC grade): Ammonium Phosphate Buffer $(0.05 \mathrm{M})(20: 80 \mathrm{v} / \mathrm{v})$ with the pH adjusted to $3.50 \pm 0.1$ The mobile phase was filtered by passing through a $0.45 \mu \mathrm{m}$ membrane filter (Millipore, Bedford, MA, USA). The flow rate was $1.0 \mathrm{~mL} / \mathrm{min}$, and the injected volume was $20 \mu \mathrm{L}$. The effluent was monitored at a dual-wavelength of $290 \mathrm{~nm}$. All analyses were carried out at $25^{\circ} \mathrm{C}$.

\section{Procedure:}

\subsection{Standard Preparation:}

$48 \mathrm{mcg} / \mathrm{mL}$ of DA and $24 \mathrm{mcg}$ of TM simultaneous standard solution was prepared by taking $40 \mathrm{mg}$ of DA and $20 \mathrm{mg}$ of TM reference standard in a $50 \mathrm{~mL}$ volumetric flask, dissolved in acetonitrile by sonication, and diluted up to mark level with diluents (mobile phase). $3 \mathrm{~mL}$ was further diluted to $50 \mathrm{~mL}$ with the same diluents to give the working range concentration of the standard solution.

\subsection{Sample Preparation:}

$2 \mathrm{~mL}$ of a well-shaken ophthalmic solution containing DM and TM was taken in a $50 \mathrm{~mL}$ volumetric flask, few $\mathrm{mL}$ acetonitriles were added and sonicated to dissolve. The sample was diluted up to the mark level with the mobile phase. Further dilution was made by diluting $3 \mathrm{~mL}$ into a $50 \mathrm{~mL}$ volumetric flask and diluting with the same dilution. The samples were prepared in triplicate and filtered through a $0.45 \mu \mathrm{m}$ membrane filter before injection into the HPLC system.

\subsection{Method Development \& Optimization:}

Separation science techniques have been the basics of excellent chromatography. One main objective is to resolve a mixture of analytes and give symmetrical peaks, better resolution, and short run time. Certain factors in chromatographic science are helpful to achieve these goals, including $\mathrm{pH}$, stationary phase, flow rate, organic solvent ratio, polarity, and detecting wavelength. Various factors related to this method, such as the composition of the mobile phase, a stationary phase with various brands, packing materials, i.e., C8 and C18, and configurations $(10,15,25 \mathrm{~cm})$, have experimented to acquired sharp peaks with the least tailing and enhanced resolution.

Initially, simple acetonitrile and water were studied in a different ratio, but the aqueous part was shifted to buffer as without buffer peak shapes were unacceptable. The impact of $\mathrm{pH}$ was also studied. It was noted that $\mathrm{pH}$ above 6 distorted the peak of dorzolamide; however, at lower $\mathrm{pH}$, the peak more or less remains symmetrical. However, the resolution was least affected. At 50:50 ratio, the peak of dorzolamide merged with timolol maleate, increasing organic portion in the mobile phase eluted timolol maleate. It gave a short run time of five minutes; however, the peak obtained was not well resolved. Gradually buffer portion was increased, which eluted dorzolamide earlier than timolol maleate. This attribute could be appropriated to the polar nature of dorzolamide. Finally, the mobile phase of buffer: ACN (80:20 v/v) was used along with Phenomenex C18 chromatographic column (4.6 X $250 \mathrm{~mm} 5 \mu \mathrm{m})$, the eluent was monitored at $290 \mathrm{~nm}$. Simultaneous chromatography was achieved in $10 \mathrm{~min}$, and it gave better peak shape, reduced tailing. Mobile phase selected from 10 minutes with excellent peak parameters (symmetry, tailing, etc.). The projected method is handy, simple, short run time, low cost and easy preparation, and less costly. The structure of DM and TM is shown in Fig. 1 a,b. different solvents were assessed for best solubility, and acetonitrile was preferred and selected because of its proportion 
in the mobile phase and no interference at the selected wavelength. Typical standard and sample chromatograms are shown in Fig.2 and 3, respectively, revealing satisfactory resolution and exhibited the best chromatography.

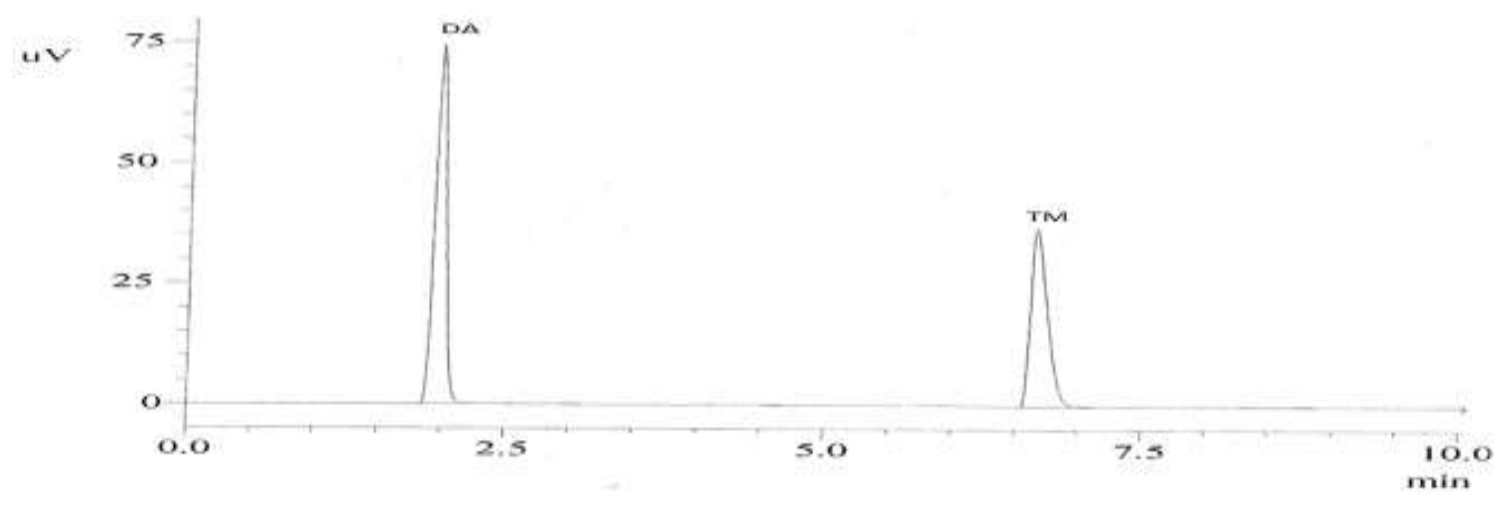

Figure 2. Standard Chromatogram

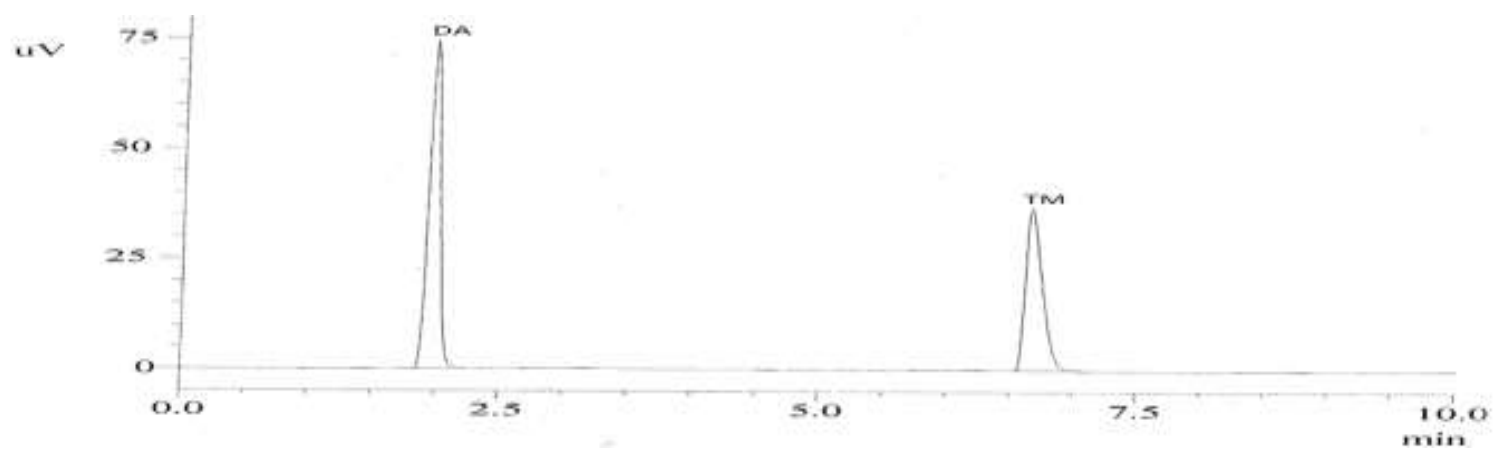

Figure 3. Sample chromatogram

\subsection{Method Validation:}

A comprehensive method validation protocol was used to establish method validation. It included linearity, range, specificity, accuracy, precision, robustness, and system suitability ICH, [16-18].

For the linearity study, the primary standard simultaneous solution was diluted in a range of 12 to $25000 \mathrm{mcg} / \mathrm{mL}$ for TM and 25 to $50000 \mathrm{mcg} / \mathrm{mL}$ for DA. The calibration curve was produced using a regression equation $(\mathrm{y}=\mathrm{c}+\mathrm{mx})$. From this equation, intercept, slope, relation coefficient was subsequently calculated [19]. To specify the study, joint recipients used in ophthalmic drops were spiked with a pre-weighed quantity of drugs. The interference of excipients in the quantification of the drugs was calculated. Multiple samples were prepared and analyzed for interference [20].

Precision is defined as the degree of agreement among individual readings when the same homogenous sample is subjected to multiple analyses. Both intraday and inter-day variations in the test method in a range of concentrations covering lower-midd-higher concentration, i.e., $80-120 \mu \mathrm{g} / \mathrm{mL}$ of nominal concentration of drug substance [21]. Both inter-day and intraday precision was assessed, and \%RSD was calculated. For this purpose, multiple samples were prepared and analyzed with the projected method. The deviation was calculated on same-day analysis and different days to document repeatability and reproducibility [22].

The accuracy of the method is defined as the closeness of test results to the accepted value. It was documented by analyzing a bulk sample in a different range of concentration and comparing obtained results with the actual value. The sample was prepared in multiple and analyzed with the projected method [23].

The sensitivity test of the method was assessed by LOD, i.e., the limit of detection, and LOQ, i.e., the limit of quantification. For this purpose, sequential diluting of the simultaneous standard solutions at decreasing concentrations in the range of $100-10 \mathrm{ng} / \mathrm{mL}$ for the drug product was prepared and chromatographed through the HPLC system. A signalto-noise ratio of 3 was established for a limit of detection, while a signal-to-noise ratio of 10 was established for a limit of quantification [24].

Deliberate variation in method parameters such as flow rate, $\mathrm{pH}$ of mobile phase, detection wavelength changes, etc., was made in method parameter to assess the method's robustness. For system suitability testing, replicated injections were made to calculate the \% relative standard deviation. Peak symmetry and resolution among peaks was established as well as theoretical plates of the column. 


\section{DISCUSSIONS:}

Well resolved peaks revealed by Fig. 1 a,b shows structure of analytes DA and TM. The combined dosage form is available in the market. It has been a mandatory choice to analyze them making all formal prerequisite to safeguard and guarantee the intactness and quality of the product. Literature studies show some scientist has worked on an individual and simultaneous analysis of these drugs molecules. However, all reported methods are not easy and straightforward and are expansive since they require gradient systems that are very expansive and could not be burdened by a low-income pharmaceutical company. Our projected method is straightforward; it involves a simple isocratic HPLC system and no hard labor and extractions.

Table-1 shows the onset of an excellent chromatographic system with a $0.48 \%$ relative standard deviation. Good peak symmetry lays around 1.0; best separation is shown at resolution in the range of 4 to 7.0 with excellent column performance at more than 35000 theoretical plates.

Table-1. Justification of system suitability studies

\begin{tabular}{|l|l|}
\hline Parameter & Value \\
\hline Mean Area & 762582 \\
\hline Standard deviation (SD) & 0.88 \\
\hline Relative Standard Deviation (RSD) & $0.48 \%$ \\
\hline Tailing factor (T) & $1.0001-1.0013$ \\
\hline Resolution ® & $4-7.0$ \\
\hline Theoretical Plates (n) & $35000-90000$ \\
\hline
\end{tabular}

Figures $2 \& 3$ exhibited excellent specificity, which the resolution value has substantiated in Table-1.

Chromatogram acquired with the excipients shows no co-eluting substance, which proves no interference from excipients. The peak of interest fulfills all the requirements of symmetrical peak confirming specificity.

Linearity study in the range of $5-50000 \mu \mathrm{g} / \mathrm{mL}$ for DA and $2.5-25000 \mu \mathrm{g} / \mathrm{mL}$ for TM behaved linearly. Peak area vs drug concentration showed a linear correlation in the assessment range. The regression analysis data are presented in Table-2; a correlation of more than 0.999 was found for both the drugs, with slope values of 12356 and 10564 for DA and TM, respectively. The low intercept values are -125.13 for DA and 100.24 for TM.

The projected method is sensitive enough to the limit of quantification as $25.43 \mathrm{ng} / \mathrm{mL}$ for DA and $15.37 \mathrm{ng} / \mathrm{mL}$ for TM, whereas the limit of detection is $7.12 \mathrm{ng} / \mathrm{mL}$ for DA and $4.72 \mathrm{ng} / \mathrm{mL}$ for TM.

Table-2. Linearity studies

\begin{tabular}{|c|c|c|}
\hline Perameter & DA & TM \\
\hline Concentration range $(\mu \mathrm{g} / \mathrm{mL})$ & $5-50000$ & $2.5-25000$ \\
\hline Correlation coefficient & 0.9998 & 0.9996 \\
\hline Slope & 12356 & 10564 \\
\hline Intercept value & -125.13 & 100.24 \\
\hline LOQ $(\mathrm{ng} / \mathrm{mL})$ & 25.43 & 15.37 \\
\hline LOD $(\mathrm{ng} / \mathrm{mL})$ & 7.12 & 4.72 \\
\hline
\end{tabular}

For evaluation of precision, different independent working range concentrations at low, mid, and high levels, i.e. $80 \%$, $100 \%$, and $120 \%$ for both drugs were analyzed multiple days by different analysts. Solutions were prepared on a fresh basis every day; as shown in Table-3.

Table-3. Accuracy and precision studies

SD value is less than $2 \%$ which granted the projected method is accurate and precise. Recovery of drug substances at

\begin{tabular}{|c|c|c|}
\hline \multirow[t]{2}{*}{ Nominal concentration } & \multicolumn{2}{|c|}{ Pharmaceutical $(n=6)$} \\
\hline & DA & TM \\
\hline $80 \%$ & $101.2 \quad 0.96$ & $97.42 \quad 1.46$ \\
\hline $100 \%$ & $101.2 \quad 0.86$ & $97.1 \quad 1.6$ \\
\hline $120 \%$ & $98.5 \quad 1.31$ & 100.2 \\
\hline Mean & $100.6 \quad 1.04$ & $97.90 \quad 1.34$ \\
\hline
\end{tabular}

three different concentration ranges as shown in Table-3, revealed good accuracy of the projected protocol. Accuracy lies in the range of 97 to $101.2 \%$. Ophthalmic drops containing these drugs were analyzed with the projected method, and test results showed that marketed products were within limits values (Table-4). 
Table-4. Pharmaceutical application studies $(n=6)$

\begin{tabular}{|c|c|c|c|c|c|c|}
\hline Parameters & Sample A & Sample B & Sample C & Sample D & Sample E & Sample F \\
\hline \% Label Claim & 99.44 & 98.3 & 101.4 & 100.5 & 99.3 & 100.1 \\
\hline \%RSD & 1.13 & 1.13 & 0.79 & 0.69 & 0.87 & 1.15 \\
\hline
\end{tabular}

The method's robustness has been shown in Table-5; results revealed that the projected method is highly robust regarding the change in wavelength, flow rate, and $\mathrm{pH}$ of the mobile phase. Results show no significant difference in the test results compared to the true value and results obtained with this projected method would not be affected by day-to-day variations in the method.

Table-5. Robustness Studies

\begin{tabular}{|c|c|c|c|c|c|c|}
\hline \multirow{2}{*}{} & \multicolumn{5}{|c|}{ Parameters } \\
\cline { 2 - 7 } & Wavelength $\mathbf{\pm 2}(\mathbf{2 9 0} \mathbf{~ n m})$ & Flow rate $\mathbf{+ 0 . 2} \mathbf{( 1 ~ m L / m i n )}$ & \multicolumn{2}{c|}{ pH $\pm \mathbf{0 . 2}(\mathbf{3 . 0})$} \\
\cline { 2 - 7 } & $292 \mathrm{~nm}$ & $288 \mathrm{~nm}$ & $1.2 \mathrm{~mL} / \mathrm{min}$ & $0.8 \mathrm{~mL} / \mathrm{min}$ & $\mathrm{pH} \mathrm{3.2}$ & $\mathrm{pH} 2.8$ \\
\hline $\begin{array}{c}\text { Mean\% recovery of } \\
\text { DA }\end{array}$ & 99.05 & 99.30 & 101.2 & 100.5 & 101.4 & 99.7 \\
\hline $\begin{array}{c}\text { Mean\% recovery of } \\
\text { TM }\end{array}$ & 99.5 & 99.35 & 101.2 & 100.5 & 100.4 & 99.8 \\
\hline SD & 1.25 & 1.32 & 1.4 & 1.2 & 1.3 & 1.2 \\
\hline RSD\% & 1.23 & 1.2 & 1.3 & 1.3 & 1.2 & 1.4 \\
\hline
\end{tabular}

\section{CONCLUSION}

The projected protocol elaborates a straightforward, convenient, and reproducible approach for the simultaneous determination of Dorzolamide and Timolol $\mathrm{HCl}$ in pharmaceutical ophthalmic formulations with excellent resolution, precision, and accuracy. The method is simple, easy, having a short chromatographic run time, and can be used for routine analysis in QC laboratory in pharmaceuticals.

\section{CONFLICTS OF INTEREST}

The authors declare no conflict of interest.

\section{ACKNOWLEDGEMENT}

Authors are very much thankful to DR. FARHAN AHMED SIDDIQUI, Senior Manager NPD, Martin Dow Pharaceuticals Pvt. Ltd. Pakistan for his technical assistance.

\section{REFERENCES}

[1] ZIMMERMAN, T. J. (1993)..Journal of Ocular Pharmacology and Therapeutics, 9(4), 373-384.

[2] Katzung, B. G. (2012). Basic and clinical pharmacology. Mc Graw Hill.

[3] Sher, N., Siddiqui, F. A., Hasan, N., Shafi, N., Zubair, A., \& Mirza, A. Z. (2014). Analytical Methods, 6(8), 27042714.

[4] Sher, N., Fatima, N., Perveen, S., Siddiqui, F. A., \& Wafa Sial, A. (2015). International journal of analytical chemistry, 2015.

[5] Sher, N., Fatima, N., Perveen, S., \& Siddiqui, F. A. (2016). Instrumentation Science \& Technology, 44(6), 672-682.

[6]. Sher, N., Siddiqui, F. A., Fatima, N., Perveen, S., \& Shafi, N. (2015). Journal of Liquid Chromatography \& Related Technologies, 38(8), 911-918.

[7] Matuszewski, B. K., Constanzer, M. L., Woolf, E. J., Au, T., \& Haddix, H. (1994). Journal of Chromatography B: Biomedical Sciences and Applications, 653(1), 77-85.

[8]Bebawy, L. I. (2002). Journal of pharmaceutical and biomedical analysis, 27(5), 737-746.

[9] Havele, S. S., \& Dhaneshwar, S. R. (2012). International Scholarly Research Notices, 2012.

[10] Maltese, A., \& Bucolo, C. (2002). Biomedical Chromatography, 16(4), 274-276.

[11] Erk, N. (2002). Journal of pharmaceutical and biomedical analysis, 28(2), 391-397.

[12] Erk, N. (2003). Die Pharmazie-An International Journal of Pharmaceutical Sciences, 58(7), 491-493.

[14] Kanchan, R., Shikha, M., Roy, N., \& Rane, R. B. (2008). Trade Science Inc, 7(8).

[15] Sharma, N., Rao, S. S., \& Reddy, A. M. (2012). Journal of chromatographic science, 50(9), 745-755.

[16] Guideline, I. H. T. (2005). Q2 (R1), l(20), 05.

[17] Sher, N., Fatima, N., Perveen, S., \& Siddiqui, F. A. (2019). South African Journal of Chemistry, 72, 130-135.

[18] Naz, A., Sher, N., Siddiqui, F. A., Kashif, M., \& Ansari, A. (2019). Microchemical Journal, 147, 797-805. 
[19] Sher, N., Fatima, N., Perveen, S., \& Siddiqui, F. A. (2019). Brazilian Journal of Pharmaceutical Sciences, 55. [20] Siddiqui, F. A., Sher, N., Shafi, N., \& Bahadur, S. S. (2017). Arabian Journal of Chemistry, 10, S2979-S2987.

[21] Siddiqui, F. A., Sher, N., Shafi, N., Wafa Sial, A., Ahmad, M., \& Naseem, H. (2014). BioMed Research International, 2014.

[22] Hasan, N., Chaiharn, M., Khan, S., Khalid, H., Sher, N., Siddiqui, F. A., \& Siddiqui, M. Z. (2013). Journal of analytical methods in chemistry, 2013.

[23] Shafi, N., Siddiqui, F. A., Naseem, H., Sher, N., Zubair, A., Hussain, A., \& Baig, M. T. (2013). Journal of Chemistry, 2013.

[24] Hasan, N., Siddiqui, F. A., Sher, N., Shafi, N., Zubair, A., \& Afzal, M. (2014). World Appl Sci J, 31(5), 730-40.

Received: $13^{\text {th }}$ January, 2020

Accepted: $22^{\text {th }}$ June, 2020 